\title{
The Syntax-IS Interface: On the Functional Discrepancies Between Clitic Left Dislocation and 'Bare Left Dislocation' in Modern Greek
}

\author{
Axiotis Kechagias \\ UCL \& University of Salford \\ a.kechagias@ucl.ac.uk
}

\section{Abstract}

Only in CLLD does the dislocated DP perform the discourse function [Topic] partitioning the utterance into [Topic] + [Comment]; cliticless non-focal dislocated DPs are solely fronted [Ground] information that partition the utterance into [Ground] + [New]. In other words, the two constructions correspond to two different information packaging strategies and grammaticalise two distinct Information Structure interface rules.

\section{Preliminaries}

Until the late nineties there had been a consensus in the literature that Greek patterned along languages like Italian and Spanish in that left dislocation of nonfocal objects is not permissible unless a pronominal clitic resumed the dislocated DP (1-3), unlike English, where this 'un-resumed' fronting is also a possibility (4):

(1) tin brizola *(tin) efara

Greek

the steak it-CL ate-1s

(2) la bistecca *(la) ho mangiato Italian the steak it-CL have-1s eaten

(3) el filete *(lo) comi Spanish

the steak it-CL ate-1s

'The steak, I ate'

(4) the steak / ate

English

\section{(cc) BY-NC-ND}


Nonetheless-despite the proliferation of these views-during the last decade there has been an overt shift in the literature of Greek. In particular, researchers like Alexopoulou and Koliakou (2002), Tsimpli and Roussou (2006) and lately Gryllia (2009), have correctly pointed out that the aforementioned assumption is actually too strong as the grammaticality of utterances like these below indicate: a non-focal object is-after all-possible to occur cliticless in a preverbal position:

(5) ti lisi vrike mono o Nikos

the solution found only the Nick

'Only Nick found the solution'

(6) ton protipuryo $\quad \theta a$ sinodefsi $o$ ipuryos aminas

the prime-minister-acc will accompany the minister-nom of-defense

'The prime minister, the minister of defense will accompany'

As far as the terminology is concerned, the construction that involves a resumptive pronominal clitic is almost invariably referred to as 'Clitic Left Dislocation' (CLLD) in the relevant literature, while the cliticless construction is sometimes referred to as Topicalisation (e.g. in Alexopoulou \& Kolliakou 2002). Although I will be coming back to this shortly, note at this early point the inconsistent pattern that arises here regarding naming: the former construction bears a label that describes (part of) its structural specification, whereas the latter construction bears a label that merely reflects its interpretive burden.

In the light of these observations the following question needs to be tackled: What exactly regulates the presence/absence of a pronominal clitic in non-focal dislocations of the type presented above? Or-in other words-what are the functional discrepancies between the two constructions? The rest of the paper is organized as follows: In section 2 I review and criticize certain major aspects of the relevant literature, while in section 3 I present the current analysis. Section 4 constitutes a short note about the syntax of the two constructions under examination and the Information Structure (IS) interface.

\section{An Overview of the Literature}

Rather expectedly after what has been discussed in section 1, while there is a good amount of work about CLLD both on syntactic and functional/ interpretive grounds, still very little has been said about 'Topicalisation' since the construction was assumed to be a non-option in Greek until quite recently. But before I start reviewing the literature's stand on the issue, let me-at this point-make an important announcement for the course of the discussion: 
From now on I will be using the term Bare Left Dislocation (BLD) to exclusively refer to and describe the type of non-focal dislocation illustrated in example (5) and (6), thus abandoning the misleading term 'topicalisation', since as we will see in what follows it is CLLDed DPs that perform the discourse function topic and not BLDed ones.

Coming into CLLD, there has always been a consensus that dislocated-tothe-left-periphery doubled DPs are 'topics', topichood being non infrequently defined in terms of 'old' or 'presupposed' information (see PhilippakiWarburton 1985). In this view, in (7) below the CLLDed DP 'ti Maria' is meant to be a topic because it corresponds to the given part of the utterance it shows up in:

(7) A: Pios filise ti Maria?

who kissed the Maria?

'Who kissed Maria'

B: [ti Maria] ti filise o Nikos the Maria her-CL kissed the Nick-nom

'Maria, Nick kissed her'

Nonetheless, this direct association of topichood with old information runs into problems, since CLLDed DPs need not always correspond to old or presupposed information. The case below illustrates this:

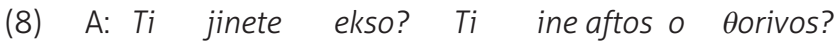

(CLLD) what happens outside? What is this the noise? 'What is going on outside? What's this noise?'

B: [kapion perastiko] ton kinizane kati skilia some passer-by him-CL chase-3p some dogs 'Some passer-by is being chased by some dogs'

Furthermore, even if this type of analysis were on the right track, it would fail to account-in a minimal at least way-for the functional discrepancies between CLLD and BLD, since even BLDed DPs typically (but not always) constitute old or presupposed information:

(9) A: pios sinodevi ton protipuryo stin Italia? who accompanies the prime-minister to-the Italy? 'Who accompanies the prime-minister to Italy?'

B: [ton protipuryo] sinosevi o ipuryos aminas the prime-minister.acc accompanies the minister of-defense 'The prime-minister, the minister of defense is accompanying to Italy' 
For reasons like these, Alexopoulou \& Kolliakou (2002) have suggested that CLLDed DPs are rather 'links' along the lines of Vallduvi (1992), that is, they indicate the entity (the 'file-card') where new information should be added and stored in an information-updating system of communication. Thus, links are necessarily part of the ground partition of the utterance upon which new information is added. The other core property of links is that their referent is supposed to be in a relation of non-monotone anaphora with the discourse along the lines of Hendriks \& Dekker (1995): a link's referent is either selected out of a discourse prominent set of entities, or is just related to some other discourse prominent entity (subselectional and relational anaphora in their terms respectively). Crucially, Alexopoulou \& Kolliakou's (2002) main claim is not only that CLLDed DPs are links but that linkhood in Greek is formally realized exclusively as CLLD, their conclusion being that BLDed ('topicalised' in their terms) DPs cannot be links. These assumptions, however, are both too strong and too weak. First, they are too strong, since there seem to be cases of felicitous CLLD constructions where neither subselectional nor relational anaphora can be established between the dislocated DP and the discourse. The example in (8) above is such a case. On the other hand, they are too weak since- if linkhood truly constitutes ground information plus non-monotone anaphora-BLDed DPs can equally (a) constitute ground material (so they function as anchor for new information giving rise to focus domains smaller than the whole utterance) and (b) stand in a relation of non-monotone anaphora with some discourse entity or set of entities. The following cases are quite revealing:

(10) A: Afto to provlima itan poli Siskolo... this the problem was very difficult

'This problem was very difficult...'

B: prarmati, na fandastis [ti lisi] vrike mono o Aris indeed, SUB] imagine-2s the solution found only the Ares 'Indeed, the solution, only Ares found'

(11) A: Pios sinodepse tus filus su sto parti? who accompanied the friends your to-the party? 'Who accompanied your friends to the party?'

B: Se Aimame jia olus; pandos [to Niko] nomizo sinodefse i Maria not remember about all though the Nick-acc think-1s escorted the Maria-nom 'I don't remember about all of them; Nick, however, I think that Mary escorted'

In the examples above, the fronted DP objects 'the solution' and 'Nick' are ground information, functioning as anchor for new information (the subject in 10; the verb and the subject in 11). Moreover, the referents of the linguistic expressions 'the solution' and 'Nick' can also be said that fulfill the non- 
monotone anaphora requirement for linkhood, since in (10) the fronted object is clearly related with the discourse salient DP 'the problem', whereas in (11) the object is meant as being selected out of a discourse salient set (i.e. the set of 'your friends'). Thus, it seems that Alexopoulou \& Kolliakou's distinction between [+Link] and [-Link] for CLLDed and BLDed DPs respectively cannot fully account for the functional discrepancy between CLLD and BLD (and there should be one), even if we assume that CLLDed DPs do indeed constitute 'links'.

The last analysis I would like to review here is Gryllia's (2009) recent contribution which constitutes the first explicit attempt towards a full understanding of the discrepancies between CLLD and BLD. In a nutshell, the kernel of this account is that both BLDed and CLLDed DPs are topics but 'of a different level'. Gryllia exploits the idea that there are two different kinds of topics, in particular topics of 'sentential level' (s-topics) and topics of 'the discourse level' (d-topics)1. An s-topic is supposed to be the expression whose referent a mere sentence is about, and is obligatorily fronted in the preverbal domain along the lines of Reinhart (1981), while a d-topic is the referent of some linguistic expression that appears to be the topic of a stretch of discourse that is larger than a simple sentence (cf. van Dijk 1977, Reinhart 1981). Although d-topics need not be marked grammaticality in Greek, they are non-infrequently marked via movement to the beginning of the clause. This is shown below:

(12) a. To 1899, o $\theta$ ios Vania ekane premiera stin Mosxa the 1899 the Uncle Vania made premiere in-the Moscow 'In 1899 Uncle Vania premiered in Moscow'

b. o Stanislavski skinotetise [D-Top tin parastasi] the Stanislavksi directed the performance 'Stanislavski directed the performance' OR b'. [D-Top tin parastasi] skinotetise o Stanislavksi the performance directed the Stanis
c. Afti $\quad$ nnorise merali epitixia it (=the performance) met big success 'It was a great success'

In the example above-according to Gryllia's analysis-the DP object [the performance] is meant to be a d-topic since the discourse continuation provided

\footnotetext{
1 Note that such a hypothesis is not unmotivated: several researchers have expressed the idea that there are different kinds of topics that do not necessarily behave alike with respect to each other, in terms of syntax, phonology and morphology. See Neeleman $\&$ van de Koot 2008, Vermeulen 2007, Frascarelli \& Hinterhölzl 2007, Bianchi \& Frascarelli 2010 among others. Cf. also Kechagias 2011.
} 
by the utterance in (c) is also about the referent of that DP. In what (b) differs from ( $b^{\prime}$ ) is that in the latter case the d-topic has moved to the preverbal domain. In this light, Gryllia (2009) then puts forward her proposal which is summarized as follows:

"[...] a preverbal object has to be taken up by a clitic in cases that it cannot be interpreted as a discourse-topic. (Gryllia 2009: 72)"

Despite the appeal that such an analysis may have at first sight, it runs into serious problems both on theoretical and empirical grounds. In what follows I will highlight only some of these. To begin with, the aforementioned statement seems to make three very specific predictions:

(13) i. A BLDed DP has to be either a (fronted) d-topic, or a d-topic and an s-topic at the same time; that is, it cannot be a mere s-topic by any means. ii. A fronted DP should be able to occur cliticless (i.e. in a BLDed fashion) when performing the function d-topic.

iii. For a DP to be interpreted as an s-level topic only, it has to show up in a CLLDed fashion.

In what follows, I will show that none of the aforementioned predictions is actually borne out by the data. Let me first show why (i) cannot be true. For the sake of the argument consider first the following example:

(14) a. Praymatopiiiike xtes o polianamenomenos ayonaston 100 metron was-held yesterday the well-expected race the-gen 100 meters-gen 'The well-expected $100 \mathrm{~m}$ race was held yesterday'

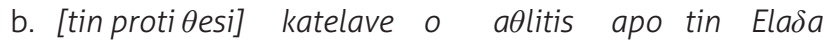
the first place occupied the athlete from the Greece 'The first place, the athlete from Greece won"

c. Prokite jia enan neo agliti pu... is for a new athlete that... 'He's a new athlete that...'

According to (i) above, the fronted object in (b) must either be a mere fronted d-topic or an s-topic and a d-topic at the same time. However, this assumption is problematic. On the one hand, I cannot see how the DP 'the first place' can be a d-topic since by considering sentence (a) one would say that the d-topic is a ' $100 \mathrm{~m}$ race'. That the DP 'the first place' cannot be a d-topic is further supported by the fact that when sentence $(c)$ is added in as a discourse continuation in Gryllia's terms, BLD in (b) is perceived as an entirely felicitous option, despite the fact that neither sentence (a) nor sentence (c) now is about 
the referent of the fronted linguistic expression 'the first place' in (b). (Indeed sentence (c) is about the athlete introduced by (b). In other words, the BLDed DP 'the first place' cannot be a d-topic contrary to what Gryllia's analysis predicts.

In the same vein, let me now show why the second of the aforementioned predictions is equally problematic. In order to do so, consider the following discourse stretch:

(15) a. O Arise exi fisiko talendo stis ksenes yloses the Ares has natural talent in-the foreign languages

'Ares has a natural talent in foreign languages'

b. isika ta aglika *(ta) milai aptesta especially the English it-CL speak-3s fluently 'English, especially, he speaks it fluently'

c. Ala endaksi, ta aglika ine sxetika efkoli ylosa... but OK, the English is relatively easy language 'But OK, English is a relatively easy language...'

Recall that, according to the second of the predictions above, an object is taken up by a clitic only when it cannot be understood as the topic of a stretch larger than a mere sentence (i.e. d-topic). In that sense, the fronted DP 'English' in (b) should indeed be a d-topic since the discourse continuation provided by (c) is also about the referent of that DP. However, not only CLLD is not banned, but actually in this particular example CLLD looks like the only option. In other words, BLD is for some reason ruled out as a possibility, despite the fact that the DP 'English' would be a d-topic according to the definition of d-topichood Gryllia adheres to.

The third prediction is not verified by the data either. According to (iii) above, for a DP to function as a mere s-topic (under the view adopted by Gryllia) it has to be taken up by a clitic; however, it seems that this is not true either. Consider the example below:
a. Pios sinodepse tin Eleni xtes sto parti? who escorted the Eleni yesterday to-the party? 'Who escorted Helen yesterday to the party?'
b. [tin aderfi tis] sinodepse sizura o Nikos... the sister her escorted-3s definetely the Nick-nom 'Her sister, definitely Nick escorted ...'
c...tin Eleni de Aimame, me sinxoris the Eleni not remember-1s me-CL forgive-2s 'As for Eleni, I don't remember, sorry' 
In clause (b) the DP object 'her sister' shows up dislocated in a BLDed fashion. According to Gryllia's analysis, one would expect that this is because that DP is meant to be the topic of the particular discourse stretch it appears in. However, considering (a) and (c) this does not seem to be the case-the discourse topic seems to be 'Eleni'. Thus, the fronted DP in (b) is not the topic of the discourse; in other words, it can only be the topic of the sentence it occurs in, that is (b). But if a fronted topic is taken up by a clitic when it does not function as a d-topic, then yet again Gryllia's account makes the wrong predictions: a DP can occur dislocated in the left periphery clitic-less, even when it clearly does not constitute a d-topic, that is, when it is a plain s-topic.

For these reasons then, I assume that the distinction between CLLD and BLD cannot be captured through this sentence-level and discourse-level topichood. In what follows I will put forward an alternative account.

\section{The Current View}

\subsection{The Analysis}

The analysis I am putting forward here is based on the idea that CLLDed and BLDed DPs participate in two distinct Information Structure mappings. In particular, CLLDed DPs are fronted Topics which associate with the IS category Comment, whereas BLDed DPs are fronted Ground that associates with the IS category New. Therefore, as far as the latter construction is concerned, I assume that the terms 'Topicalisation' or 'Discourse-Topic fronting' should be abandoned for the more descriptively accurate Ground Fronting. The idea is schematically illustrated in (17) below:

$$
\begin{array}{llll}
\hline \text { CLLD : } & {[\text { TOPIC }]} & \text { [COMMENT }] \\
\text { BLD }: & {[\text { GROUND }] \longleftrightarrow} & {[\text { NEW (or FOCUS) }]} \\
\hline
\end{array}
$$

But before I show how this binary mapping works and the predictions it makes, let me first clarify what I take the information structure categories Topic and Ground to be. Regarding topic, I am essentially adopting and adapting Reinhart's (1981) view, according to which an XP functions as topic when its referent/denotatum is meant to be 'what a sentence is about' in a given context. However, there are a couple of problematic aspects with this view that will make us eventually adjust it to some extent. The first problem has to do with the fact that under this definition of topichood we automatically lead ourselves to the commitment that all sentences should have up to one topic. However, this is 
not always the case. In (18) below it is absolutely plausible to assume that the sentence is both about 'him (=Ares)' and about 'his car'.

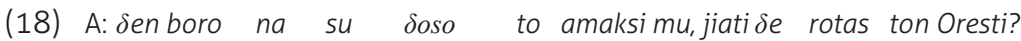
not can-1s SUBJ to-you give-1s the car my why not ask-2s the Orestes 'I can't give you my car. Why don't you ask Orestis?

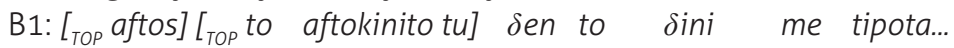
he the car his not it- $\mathrm{CL}$ give-3s with nothing

B2: [ ${ }_{\text {TOP }}$ to aftokinito tu] [ ${ }_{\text {TOP }}$ aftos] den to sini me tipota... the car his that-one-nom not it-CL gives with nothing 'That one wouldn't give his car, no matter what...'

In the same spirit, if a topic was simply 'what a sentence is about' in a given context one could wonder why, for instance, a focused element cannot be doubled by a clitic in contexts where the referent of the focused item can easily be interpreted as the entity a sentence is about. However, it is a well known property of doubling in Greek that doubled DPs cannot bear focal stress (see Tsimpli 1995, and references therein):

(19) A: leo na foreso afto to mavro pukamiso ${ }_{1}$ apopse; ti les? say-1s SUB] wear-1s. this the black shirt tonight; what say-2s 'I reckon I am gonna wear this black shirt tonight; what do you think?'

B: ne, AFTO na ("to) valis; su pai poli. Yes this SUB] it-CL put-2s to-you suits-3s well 'Yes, you should were that one; it suits you very well'

For these reasons I take topichood to be the function under which the referent of a linguistic expression is understood as being in a particular semantic-o-pragmatic relation with a predicate, namely one in which the predicate is understood as a comment about that referent in a given context. To put it differently, the predicate-comment is seen as a property ascribed on some entity, the topic. Crucially, for us topichood is the particular relation of aboutness between two categories, say a DP and a verb, rather than an absolute 'aboutness' label on some category: A syntactic block $\alpha$ is a [Topic] as long a block $\beta$ is interpreted as a [Comment]; and similarly, a syntactic block $\gamma$ is [Ground] as long as block $\delta$ is interpreted as [New]. (See also Neeleman 8 van de Koot 2008, Slioussar 2007).

(20) Topic as a Holistic Function

$[\mathrm{XP}]-[\mathrm{COMMENT}] \rightarrow \mathrm{XP}=$ Topic 
Regarding now the function Ground, I am essentially retaining Vallduvi's (1992) Information-Updating definition: Ground is that part of the utterance upon which new information is added. Ground acts as an anchor for focus. I also assume that Ground material need not be old or given information in absolute terms. Rather ground material are linguistic expressions that for contextual, situational or psychological reasons qualify as more activated in a speaker's mind as compared to the expressions that make up the rest of the utterance (see Chafe 1976, Slioussar 2007). Ground is-once again-not assumed to be a strict categorical label, but rather it corresponds to a holistic function: What makes YP a ground is the fact that the rest of the utterance is interpreted as new information, introducing new (i.e. non-evoked) referents and thus updating the discourse.

(21) Ground-hood as a holistic function

$[\mathrm{YP}]-[\mathrm{NEW}] \quad \rightarrow \quad \mathrm{YP}=\mathrm{Ground}$

In what follows I show how the aforementioned dichotomy can account in a straightforward manner for most (if not all) of the data examined so far.

\subsection{The Data}

To begin with, consider first the following example in (22) below which is originally due to Alexopoulou \& Kolliakou (2002:196):

(22) a. To kratiko Oeatro ksekinise ti ximerini sezon me tin Erofilitu Xortatsi the state theatre begun the winter season with the Erofili of Xortatsi

'The state theatre began its winter season with Erofili by Hortatsis'

b. [TOP tin parastasi] [ [COM tin skinotetise o Karolos Kun] the performance it-CL directed the Karolos Kun

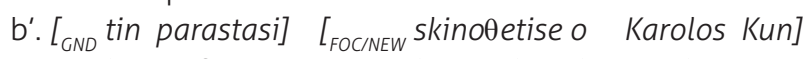
the performance directed the Karolos Kun

In the minimal context provided by sentence (a), both the IS mappings presented in (20) and (21) are available: By uttering (b) the speaker actually sees what the predicate denotes as a comment about the dislocated DP; a property is ascribed on that DP; in other words the predicate is a comment and as such a clitic shows up, since then the DP the performance has to be a topic. On the other hand, when the speaker goes for $\left(b^{\prime}\right)$, what follows the dislocated DP is not seen as a comment about that DP; rather what follows simply introduces a new referent into the discourse, namely the director of 
'the performance', updating thus the communication process².

The fact that both strategies qualify as legitimate options in this context should not come as a surprise. Topics are necessarily part of the ground partition of an utterance (i.e. doubled DPs cannot participate for instance in utterances answering all-new information questions), while the comment is the part of the utterance that typically contains new information or the focus. The fact that topics are necessarily part of the ground partition of an utterance can be rather straightforwardly accounted for by assuming that we typically comment things on after they have been first inserted into the discourse, or things that their referents are meant as salient/accessible enough (cf. Chafe 1976) either by them being physically present or situationally evoked by virtue of being, for example, related to some other discourse salient entity. Crucially, however, in a given context, it is not that all ground DPs function as topics, while, on the other hand, topics are necessarily ground material.

The idea that what follows a BLDed DP is not a comment, and by that, that the dislocated DP itself is not a topic, but rather fronted ground material, is verified by cases like the one below:
a. Praymatopiiiike xtes
o polianamenomenos ayonas ton 100 metron was-held yesterday the well-expected race the-gen 100 meters-gen 'The well-expected $100 \mathrm{~m}$ race was held yesterday'

\footnotetext{
2 As a anonymous reviewer points out "cliticless constructions of this type belong to a particular 'formal register' (e.g. news, announcements), and that one could claim that this type of register favours the precedence of cliticless non-focal material as journalists wish to keep the audience's level of interest high. As such, such data cannot be used as prototypical "neutral" examples that give support to the claims of the author". Although the observation is absolutely valid for minimal pairs such as the one illustrated above in (22) for instance, there are cases where the cliticless construction is contained in utterances without any formal flavour. For the sake of the argument, consider for instance the following two cases that arguably belong to an every-day 'common' register:

(i) i proetimasies jia to parti pane kala. O Kostas kani ta fajita, ke i Maria $\theta a$ ferita pota; the preparations for the party go well The Kostas makes the foods and the Maria will bring the drink 'The preparations for the party go well; Kostas makes the food and Maria will bring the drinks;' [ti musiki] exi analavi o aderfos mu. the music has undertaken the brother my 'My brother has been in change of the music'

(ii) A: to provlima itan pansiskolo! the problem was very-difficult 'The problem was very difficult!'

B: praymati; [tilisi] vrike mono o Nikos! indeed the solution found only the Nikos 'Indeed, only Nick found the solution!' (examples from Kechagias 2012)
} 


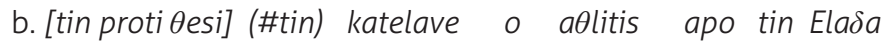
the first place (it-CL) occupied the athlete from the Greece

'The first place the athlete from Greece won"

c. prokite jia enan neo äliti pu... 'He is a new athlete that...'

In the minimal context provided by sentences (a) and (c), CLLD in (b) looks as a rather unnatural choice. Indeed, the speaker by uttering (b) does not in fact intend to make a comment about the DP 'the first place'; rather, the DP [the first place] constitutes ground information (its referent/denotatum is situationally evoked since by uttering 'the $100 \mathrm{~m}$ race' a whole network of entities is activated among which 'the first place') that rolls back all the way up to a sentence initial position so that new information is inserted into the discourse. Rather expectedly and naturally what appears as a discourse continuation in (c) is about the referent of the phrase 'the athlete from Greece'-which has just been presented as new information in sentence (b)-and not about the dislocated DP 'the first place'.

Another advantage of the line of argumentation I have been following is that it can actually account for the constrained distribution of BLD. Consider for instance the following two examples:

(24) isika ta aglika *(ta) milai aptesta especially the English it-CL speak-3s fluently 'English, especially, he speaks it fluently'

(25) tin aselfi mu *(ti) latrevo the sister mine her- $\mathrm{CL}$ adore-1s 'My sister I adore'

What differentiates the cases above from what we have seen so far is thatirrespective of what precedes or/and what follows these utterances-they are actually perceived as ungrammatical ${ }^{3}$ : the dislocated DP cannot be left cliticless, or, in other words, BLD is not an option. Although I would like to leave this issue open for a more detailed discussion in the future, I believe that this behaviour is actually predicted by the alternative account I have been sketching out: if we are correct in that BLD involves rolling up of ground material so that new information is inserted into the discourse, then lack of focus referents postverbally blocks BLD. In other words, when what follows the dislocated phrase fails to introduce new discourse referents (and presumably neither a verbal

3 And it is due to cases like these that originally BLD was dubbed ungrammatical in Greek. 
predicate nor a manner adverb can introduce referents), then it is necessarily interpreted as an attribute/property-that is a comment-about the dislocated entity-the topic. It is not a coincidence that Ground Fronting becomes very productive with orders that involve post-verbal subjects, since S-V inversion is a mechanism that many languages exploit when the subject is to be inserted into the discourse as new information (see Lambrecht 2000, Belletti 2001, and for Greek Kechagias 2011 and references there in).

\section{A Brief Note on the Syntax-C/I Interface}

As it was made clear earlier, I take topic and ground to be relational (i.e. non absolute) pragmatic functions that are furthermore not bound onto any specific region in the clause. (26) illustrates this for topic, whereas (27) illustrates this for ground:

(26) A: Pes mu kati endiposiako pu exis kani... tell-2s-imp me-gen something impressive that have-2s done

'Tell me something impressive you have done...'

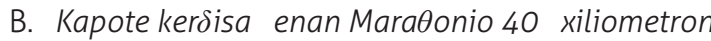
once won-1s a Marathon $40 \mathrm{~km}$-gen 'I once won a $40 \mathrm{~km}$ Marathon race'

A: Sira to prama; ki eyo to kano [Top afto] not the thing and $\mathrm{I}$ it- $\mathrm{CL}$ do this

$A^{\prime}$ : Sija to prama; $\left[{ }_{T O P}\right.$ afto] to kano ki eyo not the thing this it-CL do and I 'Big deal; this, even I can do'

(27) a. Praymatopiiiikextes o polianamenomenos ayonas ton 100 metron was-held yesterday the well-expected race the-gen 100 meters-gen 'The well-expected $100 \mathrm{~m}$ race was held yesterday'

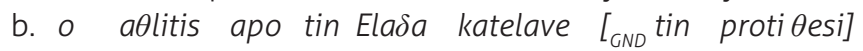
the athlete from the Greece won the first place

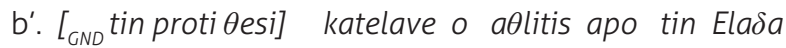
the first place won the athlete from the Greece

'The first place the athlete from Greece won'

It was also pointed out that the mapping rules in (20) and (21) are Information Structure rules, and not syntactic representations. The conceptual basis of the mapping rule in (21) lies in two well-known processing advantages associated with early mention of ground information: First, the earlier ground information occurs in the sentence, the easier it is to link it to the previous discourse. 
Second, new information is easier to integrate if the ground information that facilitates contextualization has been processed. As far as the mapping rule in (20) is concerned, as it was mentioned earlier, it is natural to typically comment something after it has been inserted into the discourse. When topic dislocations $\left(26 A^{\prime}\right)$ and ground dislocations ( $\left.27 b^{\prime}\right)$ occur in the language (and possibly across languages), they merely facilitate a transparent mapping between syntactic structures and continuous blocks of Information Structure (a la Neeleman $\&$ van de Koot 2008). Nonetheless, because the syntax and the information structure are independent modules of the grammar, this transparent mapping not infrequently can be suspended (i.e. topic and ground objects occur in-situ, since the syntax and the information structure need not be always isomorphic). Alternatively, one can assume that such orders are generated freely by the narrow syntax through generalized EPP or Edge Features (a la Chomsky 2005, 2006) and the dislocated constituents receive an interpretation at the Interface. 


\section{References}

Alexopoulou, T. and D. Kolliakou. 2002. On Linkhood, Topicalisation and Clitic Left Dislocation. Journal of Linguistics 38.2, 193-245.

Belletti, A. 2001. Inversion as Focalisation. In A.C. Hulk and J-I. Pollock (eds.), Subject inversion in Romance and the theory of Universal Grammar. New York: OUP, 60-90.

Bianchi, V. and M. Frascarelli. 2010. Is topic a root phenomenon?. Iberia: An International Journal of Theoretical Linguistics 2.1, 18-65.

Chafe, W. 1976. Givenness, contrastiveness, definiteness, subjects, topics, and points of view. In C. Li (ed.), Subject and Topic. New York, 25-56.

Chomsky, N. 2005. On Phases. Ms, MIT.

Chomsky, N. 2006. Approaching UG from below. Ms, MIT.

Frascarelli, M. and Hinterhölzl, R. 2007. Types of topics in German and Italian. In S. Winkler and K. Schwabe (eds.), On Information Structure, Meaning and Form. Amsterdam: John Benjamins, 87-116.

Gryllia, S. 2009. On the nature of preverbal focus in Greek. A theoretical and experimental approach. PhD. Diss. University of Leiden.

Hendriks, H. and P. Dekker. 1995. Links without locations: information packaging and non-monotone anaphora. In P. Dekker and M. Stokhof (eds.), Proceedings of the 10th Amsterdam Colloquium. Institute of logic, language and computation, Department of Philosophy, Universiteit van Amsterdam, 339-358. 
Kechagias, A. 2011. Regulating word order in Modern Greek: Verb-Initial and non Verb-Initial orders and the Conceptual-Intentional interface. Ph.D Dissertation, UCL. UK.

Kechagias, A. 2012. An experimental analysis of object non-focal left dislocation in Greek. (Ms.) UCL.

Lambrecht, K. 2000. When subjects behave like objects: An Analysis of the merging of $\mathrm{S}$ and $\mathrm{O}$ in sentence focus constructions across languages. Studies in Language 24.3, 611-682.

Neeleman, A. and $\mathrm{H}$. van de Koot. 2008. The nature of discourse templates. Journal of comparative Germanic linguistics 11, 137-189.

Philippaki-Warburton, I. 1985. Word Order in Modern Greek. Transactions of the Philological Society 83, 113-143.

Reinhart, T. 1981. Pragmatics and linguistics: an analysis of sentence topics. Philosophica 27, 53-94.

Roussou, A. and I.-M. Tsimpli. 2006. On Greek VSO again! Journal of Linguistics 42, 317-354.

Slioussar, N. 2007. Grammar and Information Structure: A study with reference to Russian. PhD dissertation. Utrecht institute of Linguistics OTS.

Tsimpli, I.-M. 1995. Focusing in Modern Greek. In K. Kiss (ed.), Discourse Configurational Languages. Oxford: Oxford University Press, 176-206.

van Dijk, T. 1977. Text and Context. London: Longman.

Vallduvi, E. 1992. The Informational Component. New York: Garland.

Vermeulen, R. 2007. Japanese wa-phrases that aren't topics. In R. Breheny and N. Velegrakis (eds.), UCL Working Papers in Linguistics 19, 183-201. 